\title{
EL FRENTE POPULAR Y LA INMIGRACIÓN JUDÍA A CHILE: DE LA APERTURA AL CIERRE TOTAL
}

\section{THE POPULAR FRONT AND THE JEWISH INMIGRATION TO CHILE: FROM THE ACCEPTENCE TO THE TOTAL CLOSURE}

\author{
Enrique Brahm García y Jorge Montes Arraztoa ${ }^{*}$
}

\section{INTRODUCCIÓN}

Pedro Aguirre Cerda, abanderado del Frente Popular, iniciaría su período presidencial el 24 de diciembre de $1938^{1}$. Esa fecha coincidía con un momento en el que la persecución a los judíos en la Alemania nacionalsocialista estaba alcanzando formas cada vez más radicales. En efecto, mientras durante los primeros años del régimen nazi el gobierno de Hitler se había cuidado de ejecutar, en general, actos de violencia abierta contra la población de origen semita, situación que empezó a cambiar a gran velocidad a partir de 1938 . Hasta ese momento el antisemitismo nazi se había manifestado fundamentalmente en la dictación de una profusa legislación discriminatoria, que había ido dando forma a un estatuto especial para los judíos, privándolos de una serie de derechos y de sus bienes ${ }^{2}$. Pero las acciones directas de violencia habían sido solo esporá-

\footnotetext{
* Universidad de los Andes, Chile. Correos electrónicosebrahm@uandes.cly jmontesarra@gmail.com.

1 Valencia Avaria, Luis (1986): Anales de la República (Santiago, Editorial Andrés Bello, segunda edición).

2 Pohl, Dieter (2000): Holocaust. Die Ursachen -das Geschehen- die Folgen (Freiburg-BaseWien, Herder) pp. 25ss; Longerich (1998) 65ss; Friedländer Saúl (2009): El Tercer Reich y los judios (1933-1939). Los años de persecución (trad. Ana Herrera, Barcelona, Galaxia Gutemberg) pp.163ss; Brahm García, Enrique (1986): "El derecho de propiedad en el nacionalsocialismo alemán”, Revista Chilena de Derecho, vol. $13 \mathrm{~N}^{\circ}$ 3:pp. 441 ss.
}

dicas. Ello explica que hasta 1938 la mayoría de los judíos alemanes todavía no se decidieran a abandonar su país; tenían la esperanza de que no se avanzara a los extremos ${ }^{3}$. A comienzos del año 1938 todavía vivían en Alemania unos 360.000 judíos ${ }^{4}$.

El Anschluss, la anexión de Austria a Alemania en el mes de marzo de 1938, marcaría el inicio de una nueva etapa, mucho más radical, en el proceso de persecución a los judíos 5 . Y un segundo hito fundamental en esta escalada lo constituiría la Reichskristallnacht, que tendría lugar el 9 de noviembre de 1938. Se trataba del más importante progrom contra la población judía que tenía lugar en Alemania desde la llegada de los nazis al poder ${ }^{6}$.

Estos dos acontecimientos darían un fuerte impulso a la oleada emigratoria. Estaba claro que no había lugar para la población judía en los territorios que quedaban bajo el dominio de Hitler. Solo les quedaba escapar ${ }^{7}$.

\footnotetext{
3 Pohl (2000) p. 30.

4 Friedländer (2009) p. 352.

5 Brahm García, Enrique (1999): Hitler y la Segunda Guerra Mundial (Santiago, Editorial Universitaria), pp. 103 ss.; PoHL (2000) pp. 30-31; LONGERICH (1998) pp. 162 ss.

6 Brahm (1999) p. 111; Pohl (2000) p. 31 y LONGERICH (1998) pp. 190 ss.

7 Heim, Susanne, MeYer, Beate, Nicosia, Francis R. (2010): "Wer bleibt, opfert seine Jahre, vielleicht sein Leben”. Deutsche Juden 1938-1941 (Göttingen, Wallstein).
} 
Mientras tanto el Führer daba a conocer el día 30 de enero de 1939, ante las cámaras del noticiero UFA, la más terrible y conocida de sus profecías: "Yo quisiera ser hoy nuevamente un profeta: si el judaísmo financiero internacional, dentro y fuera de Europa, consiguiera impulsar nuevamente los pueblos a una guerra mundial, el resultado no será la bolchevización de la tierra y el triunfo del judaísmo, sino la aniquilación de la raza judía de Europa” (Brahm, 2003, p. 318).

Finalmente debe señalarse, porque esto tendría una repercusión directa sobre los países hispanoamericanos, que luego de que durante 1938 lograran abandonar Alemania unos 40.000 judíos, las fronteras de la mayoría de los países europeos y las de los Estados Unidos de América, tendieron a cerrarse para la emigración judía; o, por lo menos, se establecieron cuotas muy restringidas para su recepción. Ante ello países tan lejanos como Chile pasaban a ser una alternativa válida para escapar de las garras del nazismo ${ }^{8}$. Pero hasta fines del segundo gobierno de Arturo Alessandri, también nuestro país adoptó una política que buscaba limitar al mínimo la entrada de inmigrantes judíos. En principio debían ser solo 50 familias al año, aunque no necesariamente ese número se respetara ${ }^{9}$. De hecho a través de una serie de "Circulares" emanadas del Ministerio de Relaciones Exteriores se dio forma a un estatuto jurídico particular, por el cual se sometió a reglas especiales, que no eran válidas para el común de los inmigran-

\footnotetext{
8 Pohl (2000) p. 32.

9 Nes-el, Moshé (1987): Estudios sobre el judaísmo latinoamericano (Buenos Aires-Jerusalem, Ediciones Ultra, segunda edición). p. 114; wOJAK, Irmtrud (1994): Exil in Chile. Die deutsch-jüdische und politische Emigration während des Nationalsozialismus 1933-1945 (Berlin, Metropol) p. 88.
}

tes, a los judíos que quisieran trasladarse a Chile ${ }^{10}$.

Contra esa política reaccionaría el gobierno del Frente Popular. Como señalaba el ministro de Relaciones Exteriores del mismo, Abraham Ortega, "el Gobierno surgido de las urnas de 1938 cambió radicalmente su política racial con relación a la seguida por el antiguo. El Frente Popular volviendo a la nobilísima tradición del pasado siglo quiso que el país fuera el asilo de todos los perseguidos, y a la política restriccionista del pasado Gobierno sucedió una solidaria con los hombres que han padecido horribles desgracias" (El Imparcial, 28 de mayo de 1940). Por su parte el presidente de la República, Pedro Aguirre Cerda, en su Mensaje Presidencial de 21 de mayo de 1940 , luego de recordar que "las persecuciones raciales y el estado de guerra en Europa precipitaron inopinadamente una considerable afluencia de inmigrantes a Chile, especialmente de refugiados españoles y semitas", y que la normativa vigente trataba de poner algún freno a la llegada masiva de extranjeros, concluía señalando que "por obvias consideraciones humanitarias, hubo que dar mayor elasticidad a esta restricción" (Senado, 26.6.1940, pp. 611-612). El texto citado dejaba en evidencia también que uno de los motivos del gobierno del Frente Popular para flexibilizar las cortapisas a la inmigración era el hecho de que durante el año 1939 se precipitó la derrota de la izquierda en la Guerra Civil española, y se quería dar facilidades para recibir a quienes huían de la dictadura de Franco ${ }^{11}$.

\footnotetext{
10 Sesiones del Senado 26.6.1940, p. 609.

11 Nes-EL, Moshé (2009): Estudios sobre el judaísmo chileno (Tel Aviv, Ediciones Revista de Oriente y Occidente) p. 60.
} 


\section{LOS PRIMEROS PROBLEMAS}

El cambio de la política inmigratoria por parte del gobierno de Aguirre Cerda, sobre todo en lo que se refiere a flexibilizar la normativa vigente para facilitar la llegada de refugiados judíos, se enfrentaría muy pronto a una serie de problemas.

De partida, el personal consular no sería cambiado de inmediato y tanto el director del Departamento Consular, como algunos de los cónsules más importantes, seguirían identificándose con los criterios dominantes durante la anterior administración. Más todavía, parte de este personal mantenía serios prejuicios contra los judíos y hasta algunos rasgos antisemitas. Carlos Errázuriz Ovalle, director del Departamento Consular, en oficio dirigido al cónsul general de Chile en Praga, le señalaba "que el Departamento no desea la venida de israelitas, por ricos que sean, y US. Persiste en autorizarlos a venir con cualquier pretexto" (Archivo del Ministerio de Relaciones Exteriores (AMRE), vol. 1711 A, oficio 26.4 . 1939). Mientras en otra oportunidad era muy claro en señalar que "el país no tiene interés en dar facilidades a los israelitas para que vengan a radicarse" (AMRE, vol. 1711 A, oficio 7.3. 1939).

Una actitud similar mantuvieron varios de los cónsules chilenos repartidos por el mundo. Por ejemplo, Artemio Zañartu, cónsul de Chile en Berlín, en respuesta a una solicitud que le hacía el cónsul en Amberes, le hacía ver que "no he vacilado en arriesgar mi puesto protestando por cada correo aéreo contra la inmigración judía", pese a lo cual se veía en la obligación, ante la presión del Ministerio, de seguir otorgando visas. "En consecuencia despacho desde Berlín, cada mes más de 300 judíos de la peor especie, que van a Chile sin un centavo" (AMRE, vol. 1711 B, oficio 2.5.1939). Por su parte, el cónsul en Londres alertaba sobre los "peligros envueltos en una inmigración en masa de refugiados judíos" (AMRE, vol. 1794 A, oficio 8.3.1939). Carlos Cruz, cónsul en Viena, se negaba a visar el pasaporte de un solicitante judío y de su familia aduciendo que este "iría a Chile a sumarse a la larga lista de los que llegan a nuestro país a desplazar a nuestra naciente clase media $o$ a privar a nuestro pueblo en desigual competencia, de su escaso pan" (Senado 26.6.1940, p. 625, oficio de 12.8.1939). Por su parte Cesáreo Álvarez de la Rivera, cónsul de Chile en Hamburgo, al denegar un visado, aducía que "el señor Salomón Rajcentajn es judío polaco, elemento muy poco recomendable" (Senado 26.6.1940, p. 626, oficio 25.1.1939). Todavía en una fecha tan tardía como el 25 de mayo de 1940, Juan Marín, cónsul de Chile en Shanghai, ciudad a la que habían llegado una gran cantidad de inmigrantes judíos que escapaban de las persecuciones desatadas en Europa, informaba al Ministerio: "Esta enorme masa flotante, que llega ya a los treinta mil, solo espera que alguno de nuestros países les abra sus puertas, para ir a ejercer sus conocidas actividades de intercambio, pero no productivas, en nuestro continente. Creo que la experiencia ha también demostrado ya que esta inmigración no es la que nuestro país necesita. El judío inmigrante no se resigna a irse al campo a cultivar la tierra y a ejercer oficios manuales u otra forma de trabajo físico. El es siempre un ciudadano de las grandes metrópolis que aspira a obtener sus ganancias, simplemente como intermediario de valores, pero no como creador o productor de ellos" (AMRE, vol. 1979, oficio 25.5.1940).

Habría también casos más extremos de cónsules que tenderían a identificarse, por lo menos en parte, con el antisemitis- 
mo que se estaba imponiendo en centro Europa. Por ejemplo es el caso de Gonzalo Montt Rivas, cónsul de Chile en Praga, destacado por el investigador Víctor Farías. En oficio dirigido al Ministerio de Relaciones Exteriores, en un momento en que la persecución a los judíos era cada vez más abierta y violenta, señalaba: "En resumen, Señor, los judíos vuelven al estado en que se encontraban hace unos siglos. No es de extrañarse que en el Reich se tomen estas medidas contra los israelitas, ya que es en realidad el elemento judío dominante en $\mathrm{G}$. Bretaña, EE.UU. y Rusia el que ha desencadenado esta guerra contra Alemania...” (Farías, 2003, p. 98, oficio 6.9.1941). Por lo demás también entre los nuevos funcionarios de la Cancillería, nombrados por el gobierno del Frente Popular, se pueden encontrar los típicos prejuicios contra los judíos, con los que se buscaba limitar su entrada al país. Por ejemplo, el subsecretario del Ministerio de Relaciones Exteriores, Jocelin de la Maza, en oficio dirigido al cónsul en Francia, señalaba: "La idea es que si han de venir israelitas a nuestro país, ellos sean bien seleccionados, exclusivamente entre agricultores realmente tales y no comerciantes en productos agrícolas; técnicos industriales, ya sean contratados por firmas (ilegible) o que vengan con maquinarias para establecer una industria conveniente para nuestra economía; artesanos que ejerciten un arte útil a las actividades nacionales o capitalistas que quieran invertir en empresas de conveniencia pública”. (AMRE, vol. 1711 A, oficio de febrero de 1939). Mucho más duro sonaba un telegrama enviado desde el Ministerio al cónsul en Génova, donde se decía: "Para definir concepto de hebreo, prescinda sentido religioso y biológico, no tome en cuenta certificaciones oficiales generalmente inspiradas propósitos políticos; y ríjase por conjunto circunstancias que determinan tipo universalmente individualizado por raza, hábitos, proselitismo y actividades económicas, que ahora se singulariza por ser indeseable en mayoría países de cultura occidental y que es inadaptable a nuestro medio económico-social” (AMRE, vol. 1796, telegrama 17.1.1940).

La política de puertas abiertas a la inmigración judía, favorecida en principio por el gobierno de Pedro Aguirre Cerda, se vería también complicada por la actitud que asumió cierto sector de la prensa nacional. En efecto, algunos medios empezaron a destacar en sus titulares el hecho de que estarían ingresando al país miles de judíos. Más todavía, haciendo eco a las acusaciones que planteaba el diputado Jorge González von Marees, denunciaban que detrás de todo había oscuros negociados, pues se estaría cobrando a los judíos, para otorgarles los visados, suculentas comisiones por medio de intermediarios y de una mafia que operaría dentro del mismo Ministerio ${ }^{12}$.

Pese a todos estos cuestionamientos es probable que hayan entrado al país en esos años alrededor de 12.000 inmigrantes judíos $^{13}$.

\section{EL TRASFONDO JURÍDICO}

La comisión del Senado encargada de evaluar la acusación constitucional entablada contra Abraham Ortega, ministro de Relaciones Exteriores del Frente Popular, a propósito del tema inmigratorio, era muy clara para señalar que "con respecto a los

12 La Patria 18.7.1939 y de 1.8.1939; El Diario Ilustrado 2.12.1939; El Imparcial 3.7.1939, de 2.12.1939 y de 18.1.1940. WOJAK (1994) pp. 100ss. 13 El Diario Ilustrado 22.1.1940; WojaK (1994) p. 109. 
israelitas ha existido, en el hecho, un Estatuto especial, que viene de los tiempos de la pasada Administración y por medio del cual se sometió la internación de los hebreos a reglas especiales que no eran comunes para los individuos de otras nacionalidades y razas" (Senado 26.6.1940, p. 609).

En efecto, en esos momentos se encontraba vigente la Ley de Pasaportes de 7 de febrero de 1934 y su Reglamento, aprobado por Decreto número 315 de 25 de enero de $1937^{14}$. De acuerdo a esta normativa, la visación de pasaportes de extranjeros que quisieran viajar a Chile era una atribución que correspondía exclusivamente a los cónsules chilenos en el exterior y esta se concedía sin más trámite a cualquier extranjero, salvo que se tratara de individuos que no tuvieran "una industria, profesión, aptitudes o recursos que les permitan vivir en Chile sin constituir una carga social" (Art. 21 Reglamento) o que se negaran a firmar una declaración en la que se comprometían a no inmiscuirse en la política interna de Chile ${ }^{15}$. En todo caso ni en la ley ni en su reglamento existía ninguna norma especial relativa a la inmigración judía. Sin embargo la situación cambiaría a partir del mes de julio de 1937, cuándo se hizo llegar a los cónsules la Circular Confidencial $\mathrm{N}^{\circ}$ 3, emanada del Departamento Consular del Ministerio ${ }^{16}$. La situación de los judíos se regulaba en el $N^{\circ}$ IV de la Circular, en el que se señalaba: "Respecto a los israelitas, de acuerdo con la resolución tomada por este Ministerio, solo podrán visar sus pasaportes los Consulados Generales de Hamburgo, París y Génova, con orden expresa

\footnotetext{
14 Diario Oficial 12.2.1937.

15 Inc. $2^{\circ}$ artículo $1^{\circ}$ del Reglamento.

16 AMRE, vol. 17, Circular Confidencial $N^{\circ} 3$ 3.7.1937.
}

del Departamento (Consular) para cada caso particular". Más todavía en el inciso segundo del mismo número se agregaba que si hubiera "dudas sobre el origen racial de otros inmigrantes procedentes de Alemania, los interesados en venir a Chile tendrán que acreditarlo con certificados oficiales, debiendo darse preferencia a quienes no tengan ascendientes inmediatos israelitas".

Debido a algunos problemas interpretativos derivados de la aplicación de la misma, en diciembre del mismo año 1937 , en la Circular Confidencial N ${ }^{\circ} 24$, se insistía por parte del Departamento Consular en la idea de que de lo que se trataba era de que no llegaran al país "elementos que no vengan a producir riqueza, ya sean estos comerciantes o profesionales. Tampoco se permite la venida de israelitas, ni de personas de razas de color". En relación a los judíos, recordaba el convenio a que antes se ha hecho referencia, en el sentido de que se había establecido "una cuota, de acuerdo con lo que se ha juzgado conveniente para la demografía chilena, y para ser incluido en ella los interesados deben presentarse a la $\mathrm{Hi}$ cem con el objeto de que esta institución, bajo su garantía, haga a este Ministerio la solicitud que corresponda" (AMRE, vol. 17. Circular $\mathrm{N}^{\circ} 24$ diciembre 1937).

Pese a las declaraciones de las autoridades del gobierno del Frente Popular, ya señaladas, en el sentido de que ellos practicarían una política de puertas abiertas respecto a la inmigración extranjera, incluyendo la judía, las circulares restrictivas con instrucciones a los cónsules dictadas durante el gobierno Alessandri no serían derogadas. Más todavía, da la impresión de que se las quiso usar para tener alguna herramienta que permitiera de alguna manera regular el flujo de inmigrantes que, por la situación internacional que se vivía, era cada vez más 
abundante. Así es como en una Circular sobre visación de pasaportes de 3 de julio de 1939 se reafirmaban explícitamente las restricciones impuestas al ingreso de judíos en virtud de la Circular No 3 de 1937, repitiendo prácticamente el tenor literal de la misma, ello mientras se estudiaba un nuevo Reglamento sobre inmigración ${ }^{17}$. El 13 de julio de 1939, en un oficio dirigido al cónsul en Lisboa se decía: "Absténgase absolutamente visar pasaportes israelitas" (AMRE, vol. 1728). Y en una Circular sin número de 24 de abril del mismo año, se señalaba: "Sírvase tomar nota y comunicar a Compañías Navegación que no se permitirá desembarcar en Chile a personas de nacionalidad cuya inmigración está restringida, como también a israelitas, sino cuando la visación de sus pasaportes haya sido autorizada por este Ministerio" (AMRE, vol. 1728). Todo ello no se vería desvirtuado por lo dispuesto en la Circular $N^{\circ} 12$ de 29 de julio del mismo año, que solo apuntaba a solucionar un problema específico que se había planteado ante exigencias desmedidas hechas por algunos cónsules a quienes quisieran emigrar a Chile. En ella se señalaba: "Este Ministerio ha recibido reiteradas reclamaciones de personas a quienes se ha autorizado la visación de sus pasaportes ante el Consulado de US., especialmente porque les está exigiendo el depósito ante el Consulado de las sumas que han declarado como capital posible para sus actividades en Chile. Este Ministerio encarece a US., el despacho de todas las visaciones ya ordenadas sin exigir depósitos previos ni otras condiciones que no sean las de acreditar su identidad" (El Diario Ilustrado 23.5.1940). Con esto no variaba para nada la situación de los judíos, los que seguían sometidos a un estatuto especial.

17 El Diario Ilustrado de 23.5.1940.
La preocupación por disponer de medios que permitieran a la autoridad resguardarse ante la creciente presión inmigratoria se encuentra también en el decreto $\mathrm{N}^{\circ} 640$ del Ministerio de Relaciones Exteriores, de 23 de abril de 1939 en virtud del cual se suspendía "a contar desde esta fecha y por el plazo de un año la tramitación de solicitudes particulares de inmigración, con excepción únicamente de aquellas en que extranjeros residentes en Chile, pidan autorización para que se permita entrar al país a sus padres, cónyuges, hijos y hermanos" (Senado 2.7.1940, p. 750).

Pero, al mismo tiempo, se seguía autorizando el ingreso de judíos, lo que como antes ya se ha señalado, movió a ciertos sectores de la prensa a criticar la política del gobierno en estas materias. Tomaría así forma el "affaire de la inmigración judía" (El Diario Ilustrado 5.12.1939). Ante esto el gobierno reaccionaría con el cierre completo de las fronteras. En la Circular $\mathrm{N}^{\circ} 3$ de 6 de diciembre de 1939, dirigida a todos los cónsules generales en el exterior, se señalaba: "El Ministerio ordena la suspensión de visaciones pendientes hasta nueva orden. Sírvase tomar las medidas discrecionales para impedir el embarque de judíos" (AMRE, vol. 1728). Y en un oficio con la misma fecha se informaba al cónsul en Génova que el Ministerio "ha resuelto anular y anula todas las autorizaciones visación pasaportes de judíos hasta que, eventualmente, pueda establecerse nueva modalidad para entrada esta clase de inmigrantes" (AMRE, vol. 1711). Como en esos momentos ya se encontraban viajando hacia Chile algunos buques que transportaban inmigrantes judíos ${ }^{18}$, el Ministerio se vio obligado a enviar un nuevo cable a Génova, de fecha 9 de diciembre, en el que se orde-

18 WOJAK (1994) pp. 115ss. 
naba al cónsul notificara "por escrito Compañía (de navegación) que no se permitirá en adelante desembarco puertos chilenos judíos vengan "Virgilio" u otro barco aun cuando tengan visación consular chilena" (AMRE, vol. 1711). A partir de ese momento, solo se autorizarían las visas para judíos en tránsito a Bolivia $^{19}$.

Sin perjuicio de que en el cierre de las fronteras de Chile a la inmigración judía influyó la presión de la prensa y de los partidos de oposición al gobierno de Frente Popular, no puede desconocerse que dentro de este, y más allá de la evidente flexibilización de las medidas que en este ámbito había dispuesto el gobierno anterior, también hubo quienes se movían en base a prejuicios antijudíos. Por ejemplo, en un oficio confidencial dirigido al cónsul general de Chile en los Estados Unidos, se decía que la llegada de una abundante emigración judía, unida a la de los refugiados españoles, había causado serios problemas en el "mercado de trabajo", sobre todo en el sector de los pequeños comerciantes y en el de los obreros, los que, "como es natural, no pueden ver sin protesta su suplantación por extranjeros, sobre todo por judíos tan lejanos de nuestra idiosincrasia, costumbres, idioma, etc." Ello es lo que explicaría el que se hubiera decretado la suspensión de la inmigración de todo tipo de extranjeros, hasta aprobarse el Proyecto de Ley de Inmigración presentado al Congreso ${ }^{20}$. "Por razones de diverso orden, agregaba, esta suspensión se aplica con mayor rigor a los inmigrantes judíos, que tienen más dificultad que otros inmigrantes para adaptarse a las conveniencias y posibilidades del país" (AMRE, vol. 1829, Oficio

\footnotetext{
19 AMRE, vol. 1711, cable a Génova 14.12.1939.

20 Senado 23.1.1940, pp. 1207ss.
}

Confidencial Nº 11 8.3.1940 Departamento Consular, firma Rettig).

Un año después, el subsecretario de Relaciones Exteriores, Marcelo Ruiz, se expresaba en un sentido similar, cuando aceptaba que se pudiera exceptuar de la suspensión vigente, excepcionalísimamente, a inmigrantes españoles que "llenen los requisitos de seriedad y aptitudes para trabajos agrícolas, de industrias u oficios diversos, exceptuando profesionales y comerciantes ... pero en ningún caso ciudadanos de otras nacionalidades ni menos de origen semita" (AMRE, vol. 1882 A, oficio de 8.3.1941 al Cónsul de Chile en Glasgow).

En todo caso, y pese a la suspensión vigente y a que estaba en pleno desarrollo la Segunda Guerra Mundial, durante los años 1940 y 1941 ingresarían al país más de 1.600 inmigrantes judíos, aunque a la mayoría de ellos se les impondría la condición de radicarse en ciudades del sur del país, la que no siempre se cumplió ${ }^{21}$.

Todo esto se daba en medio de una situación difícil para el Gobierno, en particular para el Ministro de Relaciones Exteriores, por las acusaciones que circulaban, sobre todo a través de la prensa, en el sentido de que la cuestión de la inmigración se habría prestado para todo tipo de abusos. En círculos ministeriales se estarían aprovechando las urgencias de los perseguidos para lucrar con ello ${ }^{22}$. Como consecuencia de lo anterior Aguirre Cerda nombró una Comisión investigadora -integrada por Pedro Lira U., Bruno Krunmenacker y Urbano Marín- la que empezó a funcionar el 19 de diciembre de 1939 y que emitiría su informe el 17 de

\footnotetext{
21 WoJaK (1994) p. 116.

22 La Patria 18.7.1939 y El Diario Ilustrado 5.12.1939.
} 
enero de $1940^{23}$. Sus conclusiones fueron que junto con el inicio del Gobierno del Frente Popular "sobrevino una inmigración libérrima, abundante e incontrolada. Prácticamente no hubo selección alguna. $\mathrm{Ni}$ siquiera la muy cruda del dinero". Todo ello se habría dado en medio del "mayor desorden y confusión” y de una gran "desorganización administrativa”. En su opinión, "los servicios públicos chilenos no estaban prevenidos para atender una dosis regular de inmigración, y mucho menos de inmigración israelita". Además podía acreditarse "la existencia innegable de negocios fraudulentos". En opinión de los comisionados, "desde hace algún tiempo han existido organizaciones o bandas destinadas a la trata de judíos" que habrían estado lucrando con la "desgracia ajena" y con los "clamores y angustias de una raza perseguida y al amparo de los sentimientos generosos de los chilenos" (El Diario Ilustrado 22.1.1940).

En medio de esa polémica el ministro de Relaciones Exteriores, Abraham Ortega, presentaría su renuncia al cargo a mediados del mes de febrero de $1940^{24}$. No contentos con ello sus opositores, encabezados por el diputado Jorge González von Marees, presentaron una acusación constitucional en su contra. En ella se imputaban al ministro Ortega "los delitos de concusión y atropellamiento de las leyes, y además el hecho de haber comprometido gravemente el honor de la nación". Además el sería "el principal y más directo responsable de las graves irregularidades cometidas por funcionarios del Ministerio de Relaciones Exteriores en la tramitación de las visaciónes consulares para la entrada al país de inmigrantes israelitas" ( $E l$ Diario Ilustrado 23.5.1940). La Comisión

23 El Diario Ilustrado 22.1.1940.

24 Valencia Avaria (1986) tomo I p. 605. especial de la Cámara encargada de informar sobre el libelo acusatorio, y la Cámara misma, desecharían de inmediato la imputación de que Abraham Ortega tuviera alguna relación o hubiera obtenido algún beneficio del tráfico de judíos que había existido, pero aceptaría los otros dos puntos de la acusación, que son los que serían presentados ante el Senado ${ }^{25}$. Los diputados habían centrado sobre todo la discusión en el hecho de que Ortega "hubiera facilitado, como nunca se había hecho antes, la internación de judíos al país; la forma perentoria en que se ordenaban las visaciones; el número considerable de personas que se incluían en cada oficio y la disminución de exigencias que, en concepto de los acusadores, habría ordenado el ex ministro acusado, con infracción de la reglamentación consular" (Senado 26.6.1940, p. 608).

Por su parte la Comisión Especial del Senado desecharía ambas acusaciones ${ }^{26}$ y en la votación en el Senado no se obtuvo el quórum necesario por lo que definitivamente la acusación no prosperó ${ }^{27}$. La verdad es que, en lo fundamental, no podía haber habido atropellamiento de las leyes desde el momento en que las normas restrictivas de la inmigración judía que habría violado el Ministro Ortega, tenían a lo más un carácter reglamentario y, en la mayoría de los casos, se trataba solo de circulares y oficios emanados del mismo Ministerio.

\section{CONCLUSIONES}

A la distancia y conociéndose hoy con nitidez cual era el terrible destino que esperaba a los judíos que se encontraban

\footnotetext{
25 El Diario Ilustrado 23.5.1940.

26 Senado 26.6.1940, pp. 605ss.

27 Senado 29.7.1940, pp. 1129ss.
} 
bajo la órbita de poder nazi, no dejan de sorprender los artilugios jurídicos con que se pretendía en Chile limitar su entrada al país. Así, como ha solido ocurrir, se hacía un uso político de la acusación constitucional regulada en el artículo 39, 1a, a), de la Constitución de 1925, al pretender que el simple hecho de no considerar algunas circulares ministeriales, que atentaban contra el principio de igualdad ante la ley, al dar forma a un estatuto jurídico especial para los judíos en materia migratorias, constituiría un "atropellamiento de las leyes". Más allá de las consideraciones legales, resulta evidente que en ciertos sectores de la sociedad chilena, tanto en la oposición como en el gobierno, existían fuertes prejuicios antijudíos. Ello ayuda a entender el porqué pese a que la política del Frente Popular, y el resultado de la misma, fuera una evidente apertura de las fronteras a la inmigración judía, que contrasta con la política restrictiva practicada en la segunda presidencia de Arturo Alessandri, se terminara por suspender, por lo menos reglamentariamente, toda forma de inmigración. 